\title{
MODELLING IMPACTS OF CLIMATE CHANGE AND SOCIO-ECONOMIC CHANGE ON THE GANGA, BRAHMAPUTRA, MEGHNA, HOOGHLY AND MAHANADI RIVER SYSTEMS IN INDIA AND BANGLADESH.
}

\author{
By \\ Paul Whitehead ${ }^{1}$, Li Jin ${ }^{2}$, Ian Macadam ${ }^{3}$, Tamara Janes ${ }^{3}$, Sananda Sarkar ${ }^{4}$, Harvey J E Rodda ${ }^{5}$, Rajiv \\ Sinha ${ }^{6}$ and Robert J. Nicholls ${ }^{7}$ \\ ${ }^{1}$ School of Geography and the Environment, University of Oxford, Oxford, UK \\ ${ }^{2}$ Geology Department, State University of New York College at Cortland, Cortland, NY 13045, USA \\ ${ }^{3}$ Met Office, Fitzroy Road, Exeter, EX1 3PB, United Kingdom \\ ${ }^{4}$ School of Civil Engineering, Kalinga Institute of Industrial Technology, Bhubaneswar 751024 (Odisha) \\ India \\ ${ }^{5}$ Harvey J.E. Rodda, Hydro-GIS Ltd, 10 Coles Lane, Chalgrove, Oxfordshire OX44 7SY, UK. \\ ${ }^{6}$ Department of Earth Sciences, IIT Kanpur, Kanpur 208016 (UP) India \\ ${ }^{7}$ Faculty of Engineering and the Environment, University of Southampton, Southampton, UK SO17 1BJ, \\ UK. \\ Email: paul.whitehead@ouce.ox.ac.uk; Fax: +44 1235 850836; Tel: +44 7972805094.
}

\section{ABSTRACT}

The Ganga-Brahmaputra-Meghna (GBM) River System, the associated Hooghly River and the Mahanadi River System represent the largest river basins in the world serving a population of over 780 million. The rivers are of vital concern to India and Bangladesh as they provide fresh water for people, agriculture, industry, conservation and support the Delta System in the Bay of Bengal. Future changes in both climate and socio-economics have been investigated to assess whether these will alter river flows and water quality. Climate datasets downscaled from three different Global Climate Models have been used to drive a daily process based flow and water quality model. The results suggest that due to climate change the flows will increase in the monsoon period and also be enhanced in the dry season. However, once socio-economic changes are also considered, increased population, irrigation, water use and industrial development reduce water availability in drought conditions, threatening water supplies and posing a threat to river and coastal ecosystems. This study, as part of the DECCMA (Deltas, vulnerability and Climate Change: Migration and Adaptation) project, also addresses water quality issues, particularly nutrients $(\mathrm{N}$ and $\mathrm{P})$ and their transport along the rivers and discharge into the Delta System. Climate will alter flows, increasing flood flows and changing pollution dilution factors in the rivers, as well as other key processes controlling water quality. Socio-economic change will affect water quality, as water diversion strategies, increased population and industrial development alter the water balance and enhance fluxes of nutrients from agriculture, urban centers and atmospheric deposition.

KEY WORDS: Ganga, Mahanadi, Climate Change, RCP 8.5, Socio-economics, Water Quality Modelling 
The delta regions of Bangladesh and India are particularly vulnerable to flooding, with large tracts of land at low elevation making the deltas vulnerable to sea-level rise. Moreover, there is the potential for extensive flooding due to enhanced cyclone activity and increased river flows or extended droughts with changes in monsoon rainfall. Deltas have some of the highest population densities in the world with often poor and vulnerable residents (Nicholls et al., 2015, 2016, Hill et al., 2018, this volume). The adaptive strategies available to delta residents (e.g. disaster risk reduction, land use management or polders) may not be adequate to cope with pervasive, systematic, or surprise changes associated with climate change. Hence large movements of deltaic people are often projected under climate change (Nicholls et al., 2018, this volume). In addition, socio-economic change such as population increases are placing increasing pressure on resources making issues of water scarcity and food production crucial components of government planning and the focus of international interest. Climate change combined with socio-economic considerations are key strategic concerns of the Intergovernmental Panel on Climate Change (IPCC) (Fifth Assessment Report IPCC, 2014). The IPCC report highlights the likely impacts of climate change and proposes a strategy for assessing future Shared Socio-economic Pathways (SSPs) and how these might interact with climate change to generate a combined effect on catchments, people and livelihoods. This strategy has already been evaluated in a global rivers study with respect to flows (Arnell et al., 2013), and has been considered in relation to both flow and water quality (Whitehead et al., 2015 a, b, Jin et al., 2015). Other studies such as by Shi et al. (2011) have examined the impacts of climate change on agricultural aspects and how they affect water quality.

The DECCMA project is concerned with the impacts of climate change and other environmental drivers across contrasting deltas in Africa and Asia. Processes of migration are analysed using survey, participatory research and economic methods. Potential migration of people is contrasted with other adaptation approaches using a stakeholder-driven and co-produced integrated assessment approach. The project study sites are the Ganga-Brahmaputra-Meghna Delta (Bangladesh and India), the Mahanadi Delta (India) and the Volta Delta (Ghana). The Ganga-Brahmaputra-Meghna (GBM) River System and the River Hooghly constitute one of the largest river basins in the world serving a catchment population of over 780 million, and is of vital concern to India and Bangladesh as it provides fresh water for people, agriculture, industry, conservation and for the Delta System downstream. In the DECCMA programme a set of physical, geographical and chemical models have been used to simulate the catchments, the river systems, the delta estuary system and the coastal ecosystems in order to gain an understanding of the complex interactions and to project future change (Nicholls et al., 2018, this volume). Given the complex flow dynamics, diversified land uses, highly variable rainfall and temperature patterns, modelling the Indian and Bangladesh River Systems is a complex task. However, there have been several modelling studies of these rivers, with a greater focus on the Ganga River System. Many of these have been funded by Government departments or international organisations, such as the World Bank, with summary papers that capture the major findings and large scale macroeconomic aspects (Sadoff et al., 2013). Also, there have been several water quality modelling studies of other Asian River Systems such as nitrogen dynamics in small Himalayan catchments (Collins et al., 1999), pollution in the Ganga and Ramganga River Systems (Whitehead et al., 2015., Jin et al., 2015, Pathak et al., 2018, this volume) and sediment fluxes and morphology of rivers (Sinha et al., 2005, Roy and Sinha, 2014). Most previous climate modelling studies over the region have used data either directly from Global Climate Models (GCMs) or data downscaled from them from a finer resolution Regional Climate Model (RCM) of approximately $50 \mathrm{~km}$. In this study, we have used data downscaled to $25 \mathrm{~km}$ from three different GCMs. 
The main advantage of the finer grid RCM is that it is better able to represent local-scale climate processes than coarser resolution models. The downscaled climate data from the RCM is used to drive catchment models to assess impacts on flows and water quality. Then socio-economic changes are considered and 3 projected future strategies for development are considered. The impact on flow and water quality can be modelled using the INCA models, and a combined assessment of both climate change and socio-economic change evaluated.

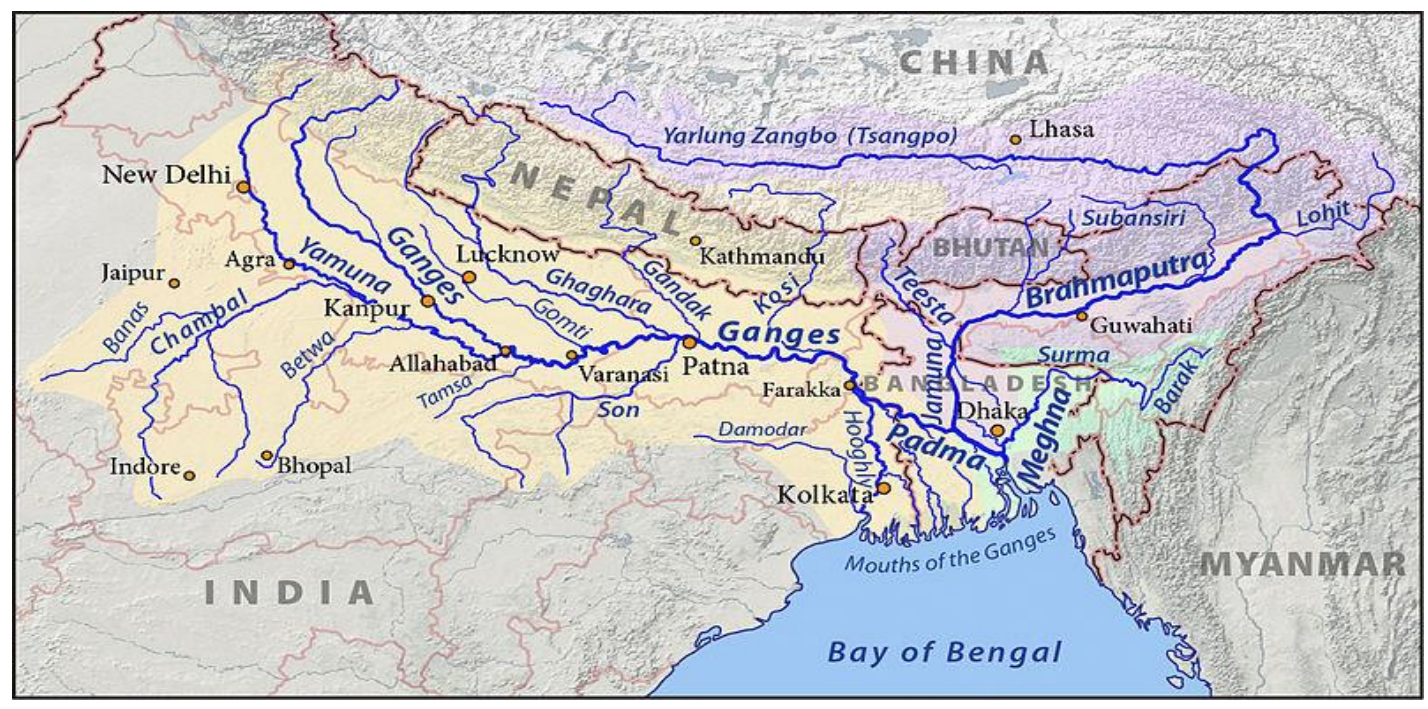

Figure 1 Map of the GBM and Hooghly Catchments Draining into the Bay of Bengal 

SYSTEMS

The GBM and associated Hooghly River System extends between the latitude of $22^{\circ} 10^{\prime} \mathrm{N}$ to $31^{\circ} 30^{\prime} \mathrm{N}$ and longitude of $78^{\circ} 0^{\prime} \mathrm{E}$ to $92^{\circ} 0^{\prime} \mathrm{E}$ in the countries of India, Nepal, China, Bhutan, and Bangladesh (Figure 1), with a total catchment area of $1,612,000 \mathrm{~km}^{2}$. The GBMH River System is considered to be one large trans-boundary river basin, even though the rivers of this system have distinct characteristics and flow through very different geographical regions for most of their lengths. The Ganga River originates from the Gangotri glacier in the Himalayas at an elevation of nearly $7010 \mathrm{~m}$ and traverses a length of about $2550 \mathrm{~km}$ (measured along the Bhagirathi and the Hooghly) before it flows southeast into the Bay of Bengal (see Figure 1). Along its way, the Ganga is joined by a number of tributaries to form the large fertile alluvial plain in North India (Figure 2). At Farakka Barrage, a major diversion delivers water from the Ganga into the Hooghly River, which them flows south into the Bay of Bengal on the Indian side. Approximately $50 \%$ of flows are diverted except during high flows $\left(>70,000 \mathrm{~m}^{3} / \mathrm{s}\right)$, with the exact diversions varying depending on inflows and season. The Farakka treaty signed between India and Bangladesh in 1996 was a significant agreement between the two countries and provides an agreed mechanism for sharing the available water. After the Farakka Barrage, the remaining flow of the Ganga plus the Brahmaputra and Meghna Rivers join and flow into the Bay of Bengal on the Bangladesh side of the delta, whilst the Hooghly flows into the Bay of Bengal on the Indian side of the Delta.

The Brahmaputra River originates on the northern slope of the Himalayas in China (Figure 3), where it is called Yalung Zangbo. It flows eastwards for about $1130 \mathrm{~km}$, then turns southwards and enters Arunachal Pradesh (India) at its northern-most point and flows for about $480 \mathrm{~km}$. Then it turns westwards and flows through Arunachal Pradesh, Assam and Meghalaya for another $650 \mathrm{~km}$ and then enters Bangladesh, where it is also called Jamuna, before merging with the Ganga and Meghna rivers. The tributaries of the Meghna River originate in the mountains of eastern India and flow southwest to join the Ganga and Brahmaputra rivers before flowing into the Bay of Bengal (Figure 1).

The Mahanadi (Figure 4) is a major east-flowing peninsular river in eastern-central India. Extending between the longitudes of $80^{\circ} 28^{\prime} \mathrm{E}$ to $86^{\circ} 43^{\prime} \mathrm{E}$ and latitudes of $19^{\circ} 8^{\prime} \mathrm{N}$ to $23^{\circ} 32^{\prime} \mathrm{N}$, the Mahanadi River System has a coverage area of $141,589 \mathrm{~km}^{2}$. The Mahanadi, which is $851 \mathrm{~km}$ in length, starts from the Dhamtari District of Chhattisgarh and drains into a delta on the east coast before flowing into the Bay of Bengal. Although the major part of the basin covers the state of Orissa and Chhattisgarh, a smaller part of the catchment lies in the states of Jharkhand, Maharashtra and Madhya Pradesh. The Mahanadi is a great source of water for irrigation, industry, domestic utilities and for producing hydroelectricity.

Bangladesh and Eastern part of West Bengal in India constitute the greatest deltaic plain in the world at the confluence of the Ganga, Brahmaputra and Meghna rivers and their tributaries. About $80 \%$ of Bangladesh is made up of fertile alluvial lowland that becomes part of the Greater Bengal Plain. The country is flat with some hills in the northeast and southeast. About $7 \%$ of the total area of Bangladesh is covered with rivers and inland water bodies and the surrounding areas are routinely flooded during the monsoon. Monsoon precipitation in the Ganga river basin lasts from July to October with only a small amount of rainfall occurring in December and January. The delta region experiences strong cyclonic 
storms, both before the commencement of the monsoon season, from March to May, and at the end of the monsoon from September to October. Some of these storms result in significant life and the destruction of homes, crops and livestock, most recently in Cyclone Sidr in 2007.

140 In Indian and Bangladesh rivers there tends to be three main sources of pollution which include household and municipal untreated sewage disposal, effluents from commercial activity or industrial sites and agricultural runoff. There is also atmospheric pollution which can be significant with Nitrogen deposition being a large factor in the nitrogen budget, and this needs to be incorporated into the modelling study.

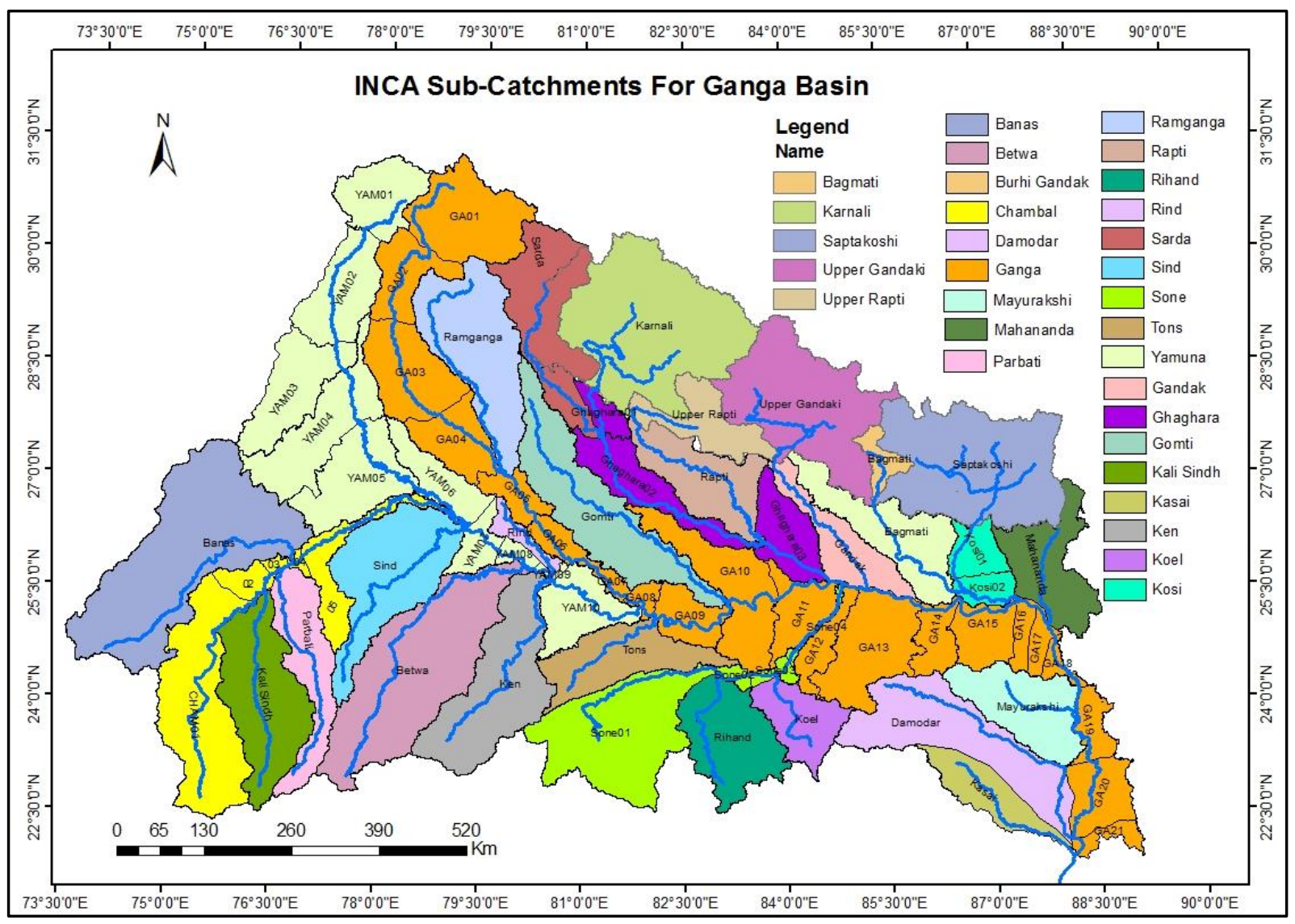

Figure 2 Map showing the multi-branch Ganga and Hooghly River System (Lower Reaches 


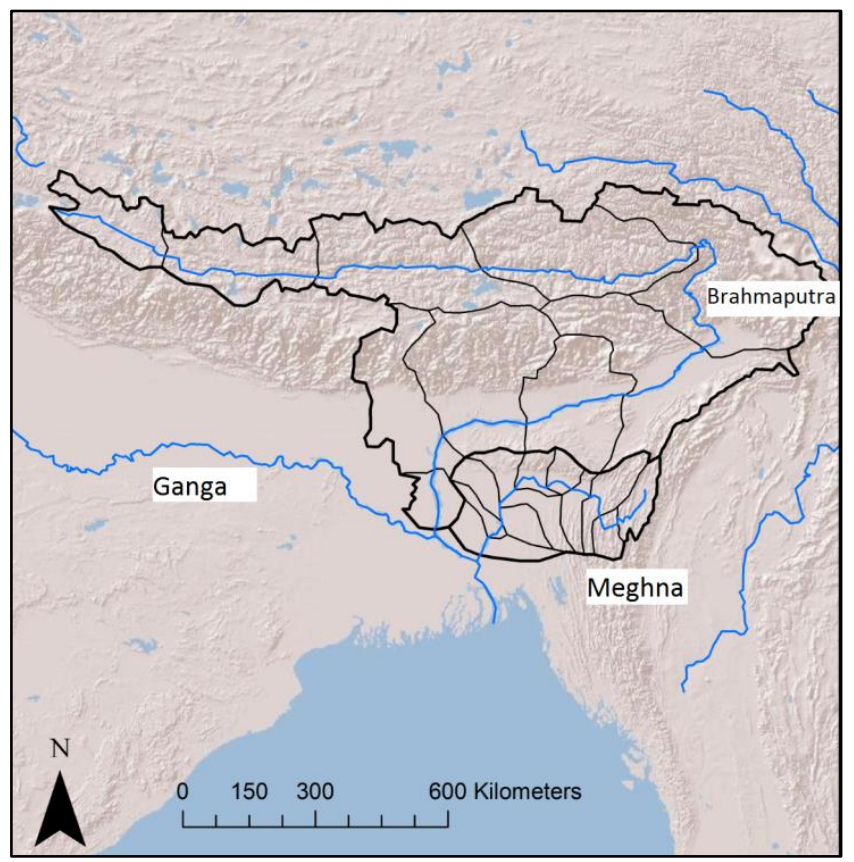

Figure 3 Map showing the multi-branch Brahmaputra and Meghna River Systems with the sub-catchment areas

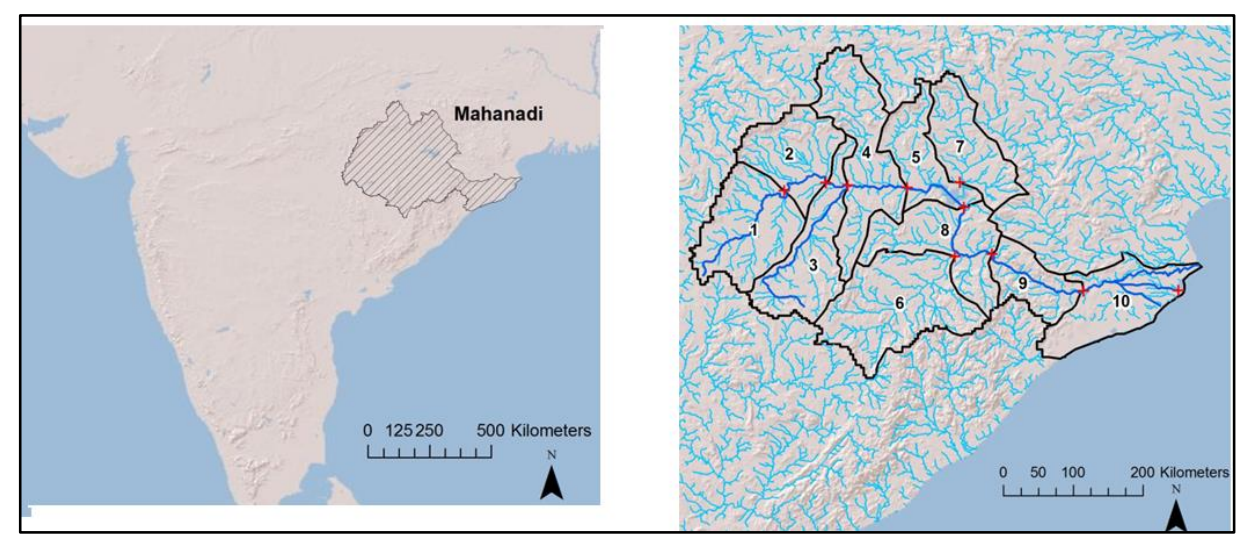

Figure 4 The Mahanadi River Basin with INCA reaches and associated sub-catchment.

\section{THE MODELLING METHODOLOGY}

Modelling complex river systems such as the Ganga, Brahmaputra, Meghna, Hooghly and Mahanadi (GBMHM) requires a semi-distributed model that can account for the spatial variability of land use and topography across the catchment. The Integrated catchment model INCA is one such model that has been applied extensively to heterogeneous catchments and has the advantage that it is dynamic, process-based and integrates hydrology and water quality (Whitehead et al., 1998 a, b, 2015, Wade et al., 2002). The INCA N and INCA P models have been developed over many years as part of UK Research Council (NERC) and EU funded projects and simulate hydrological flow pathways in the surface and groundwater systems and tracks fluxes of solutes/pollutants on a daily time step in both the terrestrial and aquatic portions of catchments. The model allows the user to specify the spatial nature of a river basin or catchment, to alter reach lengths, rate coefficients, land use, velocity-flow relationships and to vary input pollutant deposition loads from point sources, diffuse land sources and diffuse atmospheric sources. INCA originally 
allowed simulation of a single stem of a river in a semi-distributed manner, with tributaries treated as aggregated inputs. The revised version now simulates nutrient dynamics in dendritic stream networks as in the case of the GBM system with many tributaries. The model is based on a series of interconnected differential equations that are solved using numerical integration method based on the fourth-order Runge-Kutta technique. The advantage of this technique is that it allows all equations to be solved simultaneously. The INCA N and P model is described in detail (Whitehead et al., 1998, Wade et al., 2002, a, b) and a detailed application to the Ganga River is given by Whitehead et al. (2015) and by Jin et al. (2015).

\section{INCA N and INCA P SET UP FOR THE GBMHM RIVERS}

The INCA N and P models have been set up for the Ganga and Hooghly as a multi-reach model with all the tributaries and sub-catchments, as shown in Figure 2. Reach boundaries have been selected based on a number of factors such as a confluence point with a tributary, a sampling or monitoring point or an effluent input or an abstraction point associated with a major irrigation scheme or a large city. Digital terrain maps (DTMs) have been used to establish the sub-catchment boundaries. For the Brahmaputra, the Meghna, a similar multi-reach model set up has been established, as illustrated in Figure 3, which shows all the reach boundaries and sub catchments. The land use data have been derived using a $1 \mathrm{~km}$ grid resolution DTM with land cover data generated from the MODIS satellite and direct discharges of effluents are incorporated into the INCA model set up. For the Mahanadi the reach structure is shown in Figure 4. Further details of the Mahanadi setup and flow and water quality simulations are given by Jin et al. (2018, this volume). Input data for the rivers modelled has been obtained as shown in Table 1.

Table 1 Data Sources for the River Modelling Study.

\begin{tabular}{|c|c|}
\hline Data Required & Data Source \\
\hline $\begin{array}{l}\text { Digital Terrain Model (DTM) of the Study } \\
\text { Area }\end{array}$ & SRTM $90 \times 90$ m resolution raster data. \\
\hline Landuse and Land cover for Ganga basin & $\begin{array}{l}\text { National Remote Sensing Centre (NRSC) } 56 \text { x } 56 \text { Resolution } \\
\text { Grid raster data. }\end{array}$ \\
\hline Sewage Treatment Plant & $\begin{array}{l}\text { Design capacity, nitrate and ammonium concentration of outlet } \\
\text { of STPs from the reports of Central Pollution Control Board. }\end{array}$ \\
\hline Crop growth data & $\begin{array}{l}\text { FAO and Ministry of Agriculture Reports- Kharif crops - April- } \\
\text { September, Rabi Crops- October to March, Double/Triple } \\
\text { Crops \& Plantation throughout the year. }\end{array}$ \\
\hline Fertilizer input data & $\begin{array}{l}\text { Fertilizer used for the different crops available from FAO and } \\
\text { Department of Fertilizers, Ministry of Chemicals and } \\
\text { Fertilizers, Govt. of India. }\end{array}$ \\
\hline Discharge & $\begin{array}{l}\text { Observed discharge value (1979-2000) at the Hardinge Bridge } \\
\text { in Bangladesh is available from CEGIS in Bangladesh, } \\
\text { Observed Data of Mean Annual Discharge (1968-2000) is } \\
\text { available at } 5 \text { Ganga river stations. }\end{array}$ \\
\hline Water quality Data & $\begin{array}{l}\text { Data available from the Indian Central Pollution Control Board. } \\
\text { Annual maximum, minimum and mean } \mathrm{NO}_{3}-\mathrm{N}(2003-2011) \text { at } \\
\text { various monitoring stations along Ganga river. Annual } \\
\text { maximum, minimum and mean } \mathrm{NH}_{3}-\mathrm{N}(2003-2007) \text { at various } \\
\text { monitoring stations along Ganga River. Monthly } \mathrm{NO}_{3}-\mathrm{N} \text { and } \\
\mathrm{NH}_{3}-\mathrm{N} \text { data }(2010-2013) \text { for few stations in West Bengal. }\end{array}$ \\
\hline Meteorological & $\begin{array}{l}\text { Daily Soil Moisture Deficit (SMD, mm), Hydrologically Effective } \\
\text { Rainfall }(\mathrm{HER}, \mathrm{mm}), 1.5 \mathrm{~m} \text { Mean Air Temperature }\left({ }^{\circ} \mathrm{C}\right) \text { and }\end{array}$ \\
\hline
\end{tabular}




\section{CLIMATE DATA}

To give information about future hydrological conditions, INCA N requires as input a daily time series of catchment-average data describing relevant aspects of the future climate, namely precipitation, HER, temperature and soil moisture deficit (SMD). The model uses these data in smd

gical routines that calculate the sub-catchment river flows. The IPCC Fifth Assessment Report used the latest generation of GCMs to provide future projections of precipitation and temperature for all regions of the world, including over the GBMHM catchments (IPCC, 2014). However, GCMs typically have coarse spatial resolutions with horizontal grid boxes of a few hundred kilometres in size, and cannot provide the high-resolution climate information that is often required for climate impact and adaptation studies. The use of an RCM, which dynamically downscales the GCM simulations through being driven using boundary conditions from GCMs, can provide higher resolution grids (typically $50 \mathrm{~km}$ or finer) and is better able to represent features such as local topography and coast lines and their effects on the regional climate. There have been relatively few climate impact studies focused upon the Ganga River linked to the Bangladesh region that have used RCM output. Whitehead et al. (2015) used the $25 \mathrm{~km}$ resolution data over south Asia for the period 1971-2099 downscaled by the Met Office using the PRECIS RCM system. The RCM is based on the atmospheric component of the HadCM3 GCM (Gordon et al., 2000) with substantial modifications to the model physics (see Jones et al. 2004 for details). The RCM was validated by comparing model output temperature and precipitation during the summer monsoon season with observational datasets, as described by Caesar et al. (2015).

For the DECCMA project, PRECIS has again been used to downscale GCM simulations to a resolution of $25 \mathrm{~km}$. In this study, three different GCMs have been downscaled to span the uncertainty in GCM-simulated future climate changes for the region, namely CNRM-CM5, GFDL-CM3 and HadGEM2-ES (Janes et al., 2018, this volume). Janes et al. (2018, this volume) have validated the three RCM simulations against precipitation and temperature observations covering northern India and Bangladesh and have found that all three RCMs reproduce the timing of the wet/dry and warm/cool seasons in the region, except for a delay in the wet season in the simulation forced with GFDL-CM3. Differences between the simulation outputs and observations differ in their detail, but all three simulations are slightly too dry during the monsoon season in many areas and slightly too cold throughout the year. In the Himalayas, in common with other RCM simulations performed for this region, all three simulations are wetter and colder than the observed climate, though deficiencies in observational datasets may contribute to these apparent biases.

The GCM simulations downscaled are of Representative Concentration Pathway 8.5 (RCP 8.5), which has been selected as the main focus of the DECCMA project in order to consider the strongest climate change signal (Kebede et al. 2018, this volume). RCP 8.5 is consistent with greenhouse gas emissions continuing to rise throughout the 21 st century and represents a relatively challenging situation for climate change adaptation, but one that does not appear unrealistic given recent changes in the Paris Climate Accord. 
234 In addition to the climate impacts we need to consider the effects of changing socioeconomics. Population change, industrial development, agriculture and land use change will all affect flows and water quality in River Systems and these changes will eventually also impact coastal systems. In terms of the socio-economic scenarios, three narratives have been defined in DECCMA based on the IPCC Shared Socio-economic Pathways or SSPS (IPCC, 2014). The three SSP scenarios have been selected based on medium economic growth (SSP2), medium plus with some higher economic growth (SSP5), and medium growth minus with a lower economic growth ( SSP3), all up to the 2050s. Beyond 2050, SSP5 is considered as the most likely scenario consistent with RCP 8.5. In the Indian and Bangladesh catchments there are many factors that affect the socio-economic conditions and potential futures from a flow and a water quantity perspective. These include population change and public water use, effluent discharge, water demand for irrigation and public supply, land use change, atmospheric deposition driven by industrial development or GDP and water transfer plans. Each of these aspects of socio-economic change need to be considered for the GBMHM catchments and a comprehensive description of the socioeconomic assumptions are given elsewhere (Kebede et al., 2018, this volume). The following sub-sections present brief description and summary details of the catchmentspecific scenarios and data considered.

\section{Population}

Population forecasts for Indian States vary widely depending on assumptions about fertility rate and economic wellbeing. UNDP population projections for 2041-2060 and 2080-2099 and other socio-economic factors indicate a wide range of population growth (Kebede et al., 2018) and these are indicated in Table 2, showing a large increase under the low economic growth scenario and a much reduced rate under better economic conditions. Population increase also drives domestic effluent discharge, although the percentage of people moving to urban areas, where there are constructed sewerage systems, is an important factor. In general it is thought that the trends towards urban living will continue, with over $50 \%$ of the population living in urban areas in the future. The upgrading of Sewage Treatment Works (STWs) is also an important factor affecting water quality, with tertiary treatment being progressively installed in modern STWs, thereby reducing the phosphorus loads into rivers from these works by $86 \%$. The Ganga Cleanup and Management Plan aims to considerably upgrade the sewerage and treatment processes. Assuming the secondary treatment processes are introduced, average ammonia discharge concentrations should fall from 19 $\mathrm{mg} / \mathrm{l}$ to $5 \mathrm{mg} / \mathrm{l}$. Nitrate is likely to stay much the same unless $\mathrm{N}$ tertiary treatment is implemented, which is very expensive. STWs can also be designed to remove phosphorus and a reduction from $5 \mathrm{mg} / \mathrm{l}$ to $1 \mathrm{mg} / \mathrm{l}$ is highly likely as part of the cleanup process.

\section{Water demand for irrigation and public supply}

The demand for public water supply will increase with population growth, although much of the supply in rural areas is from groundwater. Changes in irrigation water demand reflect changes in agriculture and land use. However, agricultural changes in India are difficult to predict as any changes will depend on factors such as world food prices, which are driven by increasing global population, potential food scarcity and how farmers react to changing crop prices. Other key influential factors include technological developments, such as the 
introduction of new crop varieties adapted to changing local environmental conditions. The Food and Agriculture Organization of the United Nations (FAO) estimates a $22 \%$ rise in $\mathrm{Kcal} /$ person/day in food production in India by 2050 (FAO, 2013) with much of this from increased production of dairy and meat, as well as additional crops producing vegetable oils and sugar. Agricultural expansion and intensification will be required to feed a growing population. It is assumed in the medium scenario that new improved crop yields and more efficient farming will occur, and irrigation abstraction from the rivers and groundwater will increase. For the purposes of this study we have assumed that the abstraction from the Ganga River will increase by $22 \%$ on average but will vary slightly between scenarios.

\section{Atmospheric Nitrogen Deposition}

Atmospheric nitrogen pollution has become an increasing problem around the world, as industrial development, power generation and ammonia release from intensive agriculture has expanded. For example, across Europe, a set of Nitrogen Protocols have been established by the UN/ECE Commission of Transboundary Pollution and these protocol have been agreed and implemented by all EU countries. Deposition can be high with $15 \mathrm{~kg}$ $\mathrm{N}$ per hectare per year being deposited in certain parts of Europe such as the UK. The effect of high atmospheric $\mathrm{N}$ is to alter the terrestrial ecology of plants and natural vegetation, and provide a baseline source of $\mathrm{N}$ to groundwaters and streams, which can then affect aquatic ecology. Research in the Himalayas, in which INCA N was applied to a range of basins, suggests generally low concentrations of atmospheric N, but across India, levels are likely to be much higher, with greater urban and industrial sources of atmospheric $\mathrm{N}$ (Whitehead et al., 2015). In the future, increased industrial development and more intensive farming methods will cause atmospheric $\mathrm{N}$ concentrations to increase. INCA N can incorporate these effects as deposition loads to the sub-basins, and thus $\mathrm{N}$ levels have been altered to reflect the different socio-economic scenarios into the future. It has been assumed that $N$ deposition rates are 8,10 , and $6 \mathrm{~kg} / \mathrm{ha} /$ year for the three scenarios with medium growth, plus and minus, respectively.

\section{Land use change}

Kathpalia and Kapoor (2010) and the FAO (World Agriculture Report 2013) reviewed projected changes in agriculture in India. Their predicted changes in agriculture translate into crop production and land use change across the basins. In general, they predict modest changes in land use reflecting the fact that land in India is already used intensively for growing a wide range of crops. They predict modest reductions in forest cover but an increased area of double/triple crops to meet enhanced food demands, as indicated in Table 2.

Table 2 Summaries of three socio-economic scenarios for the catchments, under medium, medium plus and medium minus development for the 2050s and the 2090s.

\begin{tabular}{|l|c|c|c|c|c|c|}
\hline & \multicolumn{2}{|c|}{ Medium } & \multicolumn{2}{c|}{ Medium + } & \multicolumn{2}{c|}{ Medium - } \\
\hline & 2050 s & 2090 s & 2050 s & $2090 s$ & 2050 s & $2090 s$ \\
\hline $\begin{array}{l}\text { Population } \\
\text { change }\end{array}$ & $33 \%$ & $29 \%$ & $58 \%$ & $108 \%$ & $16 \%$ & $-8.4 \%$ \\
\hline
\end{tabular}




\begin{tabular}{|c|c|c|c|c|c|c|}
\hline $\begin{array}{l}\text { STW flow and } \\
\text { design for water } \\
\text { quality control } \\
\text { (given urban \% } \\
\text { change) }\end{array}$ & $\begin{array}{c}\text { flow } \\
\text { increase by } \\
33 \%\end{array}$ & $\begin{array}{c}\text { flow } \\
\text { increase by } \\
29 \%\end{array}$ & $\begin{array}{c}\text { flow } \\
\text { increase by } \\
58 \% \text { and } P \\
\text { at } 1 \mathrm{mg} / \mathrm{l}\end{array}$ & $\begin{array}{c}\text { flow } \\
\text { increase by } \\
108 \% \text { and } \\
\mathrm{P} \text { at } 1 \mathrm{mg} / \mathrm{l}\end{array}$ & $\begin{array}{c}\text { flow } \\
\text { increase } \\
\text { by } 16 \%\end{array}$ & $\begin{array}{c}\text { flow } \\
\text { decrease } \\
\text { by } 8.4 \%\end{array}$ \\
\hline $\begin{array}{l}\text { Water demand } \\
\text { for irrigation and } \\
\text { public supply }\end{array}$ & $\begin{array}{c}\text { abstraction } \\
\text { increase by } \\
22 \%\end{array}$ & $\begin{array}{c}\text { abstraction } \\
\text { increase by } \\
22 \%\end{array}$ & $\begin{array}{c}\text { abstraction } \\
\text { increase by } \\
25 \%\end{array}$ & $\begin{array}{c}\text { abstraction } \\
\text { increase by } \\
30 \%\end{array}$ & $\begin{array}{l}\text { abstraction } \\
\text { increase } \\
\text { by } 18 \%\end{array}$ & $\begin{array}{c}\text { abstraction } \\
\text { increase by } \\
18 \%\end{array}$ \\
\hline $\begin{array}{l}\text { Atmospheric } \\
\text { deposition of } \mathrm{N}\end{array}$ & $\begin{array}{c}8 \mathrm{~kg} \\
/ \text { ha/year }\end{array}$ & $\begin{array}{l}12 \mathrm{~kg} \\
/ \text { ha/year }\end{array}$ & $\begin{array}{l}10 \mathrm{~kg} \\
/ \text { ha } / \text { year }\end{array}$ & $\begin{array}{l}15 \mathrm{~kg} \\
/ \text { ha/year }\end{array}$ & $\begin{array}{c}6 \mathrm{~kg} \\
\text { /ha/year }\end{array}$ & $\begin{array}{c}9 \mathrm{~kg} \\
/ \text { ha/year }\end{array}$ \\
\hline $\begin{array}{l}\text { Int. Agric. Land } \\
\text { Use Change }\end{array}$ & \begin{tabular}{l}
\multicolumn{1}{c}{$5 \%$} \\
increase in \\
agriculture
\end{tabular} & $\begin{array}{l}7 \% \\
\text { increase in } \\
\text { agriculture }\end{array}$ & \begin{tabular}{c}
\multicolumn{1}{c}{$7 \%$} \\
Increase in \\
agriculture
\end{tabular} & $\begin{array}{c}10 \% \\
\text { increase in } \\
\text { agriculture }\end{array}$ & $\begin{array}{l}4 \% \\
\text { increase in } \\
\text { agriculture }\end{array}$ & $\begin{array}{c}6 \% \\
\text { increase in } \\
\text { agriculture }\end{array}$ \\
\hline
\end{tabular}

The INCA N and P models have already been set up for the Ganga River as part of a separate study (Whitehead et al., 2015, Jin et al., 2015) and used to model the hydrology, nitrate and ammonia, phosphate in all the tributaries and the main river systems. This study required setting up the INCA N and P model for the Ganga, Brahmaputra, Meghna, Hooghly and Mahanadi using a complex reach structure, as shown in Figures 2, 3 and 4. Details of the Mahanadi application are given by Jin et al. (2018, this volume). The daily precipitation and temperature data from the RCMs have been averaged across the study catchments and these data then used to calculate evapotranspiration rates, hydrologically effective rainfall (HER) and soil moisture deficit (SMD) using the PERSIST model (Futter et al., 2015). The PERSIST model is a daily hydrological model that can be calibrated against observed flows and is driven by daily precipitation and temperature. Key outputs of the model are the daily Hydrologically Effective Rainfall (HER) and the daily SMD and these data sets can then be used to drive the daily INCA model hydrology. This analysis process has been applied to all the GBMHM catchments and the daily HER, SMD and temperature data then used drive INCA N and INCA P. The simulations from the catchment models have then been provided for the downstream coastal modellers in order to assess impacts of climate change on the coastal systems. Details of the model calibration and validation for both flow and water quality are given by Whitehead et al. (2015) and Jin et al. (2015, 2018, this volume). The observed flow and quality data is sparse on the Indian and Bangladesh River systems, although there is a flow gauge on the Brahmaputra at Bahadurabad. Table 3 shows calibration and validation statistics plus N-S statistics (Nash and Sutcliffe, 1970) fits to the observed data for the Ganga River system at 4 locations

Table 3 Statistics of Model Fit for Flow on the Ganga at 4 locations

\begin{tabular}{|c|c|c|c|c|}
\hline $\begin{array}{c}\text { Ganga River } \\
\text { Locations }\end{array}$ & $\mathrm{R}^{2}$ & $\mathrm{~N}-\mathrm{S}$ & $\begin{array}{c}\text { Flow calibration } \\
\mathrm{R}^{2}\end{array}$ & $\begin{array}{c}\text { Flow validation } \\
\mathrm{R}^{2}\end{array}$ \\
\hline Kachlabridge & 0.6 & 0.49 & 0.6 & 0.54 \\
\hline Ankinghat & 0.73 & 0.66 & 0.56 & 0.51 \\
\hline Kanpur & 0.56 & 0.45 & 0.49 & 0.49 \\
\hline Hardinge bridge & 0.73 & 0.49 & 0.73 & 0.7 \\
\hline
\end{tabular}


Figures 5 and 6 show typical results for flows and nitrate simulations and fits to the observed data. The $\mathrm{N}$ load calculations in Figure 6 are based on simulated and observed Nitrate- $\mathrm{N}$ concentrations and flows. In this study, three 20 year time slices have been evaluated using 1981-2000 as a baseline period, with 2041-2060 as a future mid-term time slice and the period 2079-2098 as a far future time slice.

\section{Model uncertainty analysis and limitations}

There are always issues concerned with model uncertainty and model limitations in any flow and water quality modelling study. Models are a simplification of reality and allow an approximation to any system to be evaluated (Whitehead et al., 2016). The fact that the system is dynamic and that chemical processes are kinetic in nature and interact with the hydrology makes modelling a very complex process. There have been extensive studies of uncertainty using the INCA models with techniques such as generalized sensitivity analysis (Spear and Hornberger, 1980, Hornberger and Spear, 1980) used extensively to test INCA model uncertainty (Rankinen et al. 2006, Futter et al. 2007, Wade et al. 2002 a, b, c) to evaluate both parametic uncertainty in the INCA Model and uncertainty in the data used to drive the model. For example, Wade et al. (2002a) found that the INCA N model performance was sensitive to the parameters defining nitrogen dynamics such as denitrification processes as well as key hydrological factors such as base flow index. There are limitations in any water quality modelling study because of all the complexities. In this study a key limitation is the lack of frequent water quality data to allow a full calibration and validation of the model and even the flow data is fairly limited. So there will be uncertainty in any results from such a study.

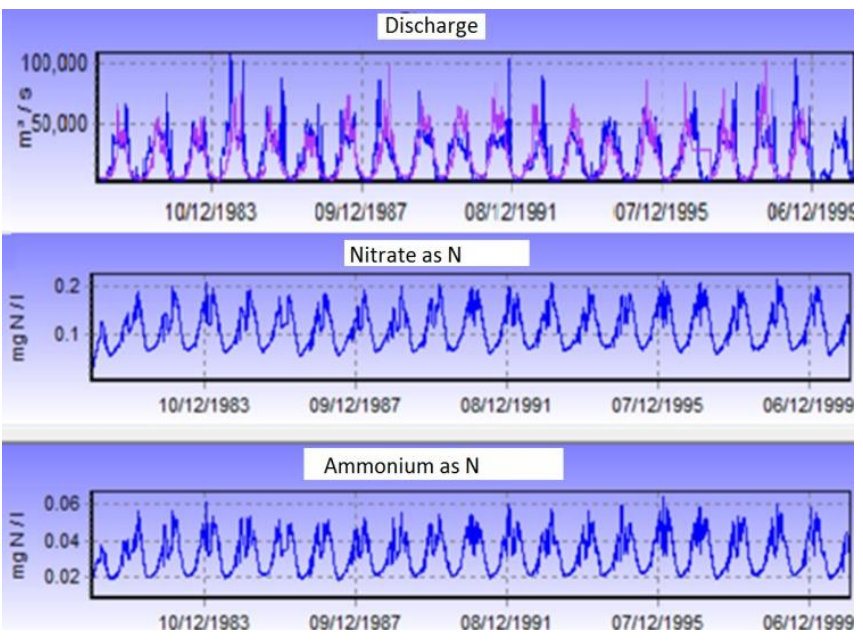

Figure 5 Simulated (blue line) and Observed (purple line) daily flows at the Flow Gauge on the Brahmaputra River System at Bahadurabad for 1981-2000 together with simulated 


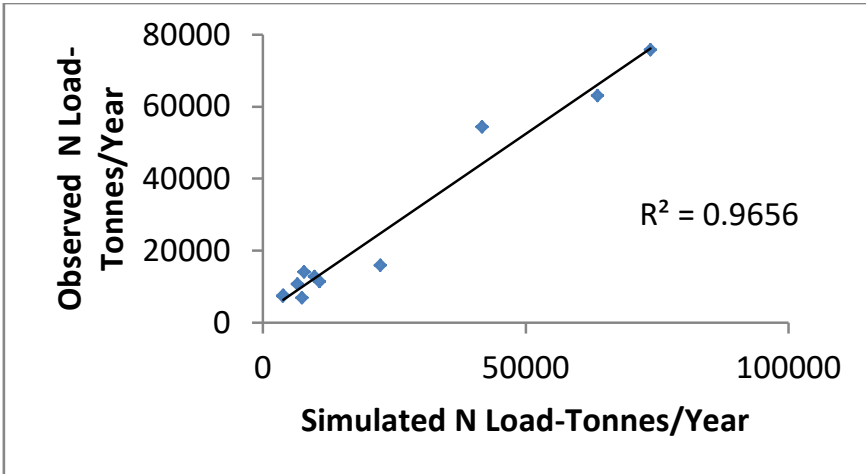

Figure 6 Simulated and Observed Loads in the Ganga River at Kanpur

\section{EFFECTS OF CLIMATE AND SOCIO-ECONOMIC CHANGES ON RIVER FLOW}

With 5 rivers to compare and 3 Climate Scenarios plus 3 socio-economic scenarios there are many combinations of results to discuss for flow and water quality. Here we discuss a limited set but they capture the likely changes as suggested by the modelling analysis. Figure 7 shows the impacts of climate change on flow in the 5 River Systems using the climate data downscaled from HadGEM2-ES. The Brahmaputra simulated monthly mean flows in Figure 7 show relatively little change into the future for the 2050s and into the 2090s. However, the pattern of monthly flows is quite different for the Ganga, the Hooghly and the Mahanadi which all show limited changes by the 2050s, but significant increases in monsoon flows in the 2090s, reflecting higher precipitation in the monsoon period (Janes et al., 2018, this volume).

Table 3 shows changes in extreme flow for the downscaled GFDL-CM3 GCM. It compares the extremes of behaviour with the statistic Q95 representing the low flow or drought conditions and Q5 representing the high flow or flooding conditions. The simulated flow values are shown in the Table 3 together with the percentage change in Q95 and Q5 by the 2050 s and the 2090s. The high flow conditions (Q5) show a modest increase in the 2050s in all rivers and a very large change in the 2090s, suggesting that flooding will significantly increase. With regard to low flows, there are differing patterns of behaviour, with the Brahmaputra, Meghna and the Mahanadi showing significant increases by the 2050s and all rivers showing increases by the 2090s. This initially suggests an easing of water security issues, but these results do not take into account the socio-economic changes where increased water use for irrigation and public use will lower baseflow conditions. The socioeconomic effects are considered below in terms of flow and water quality.

An interesting result is the comparison of the 3 downscaled GCMs (CNRM-CM5, GFDL-CM3 and HadGEM2-ES). Each of these generates different time series of precipitation, temperature and evaporation (Janes et al., 2018, this volume), and these also vary from catchment to catchment. Figure 8 shows the variation between the regional climate model output in terms of flow in the 5 different rivers. Results for the downscaled CNRM-CM5 and HadGEM2-ES GCMs are remarkably similar in terms of flow changes by the 2050s. However, results for the downscaled GFDL-CM3 GCM show lower flows in the Ganga and Hooghly Rivers.

The effects of socio-economic changes on river flows is illustrated in Figure 9, which shows the 2050s total flows for the combined Ganga, Brahmaputra and Meghna in Bangladesh. 
The effects of the socio-economic factors are fairly minimal by the 2050s and are outweighed by the increased flows due to climate change. However, if the effects of major water transfer schemes are considered, such as a $30 \%$ diversion of the Brahmaputra flows, then then there is a significant reduction in flows in Bangladesh. This could be quite serious in Bangladesh and especially in the low flow period when the water is used in Bangladesh for irrigation and is a key freshwater driver for fisheries in the rivers and estuary systems. Note in Figure 9 the 3 socioeconomic scenarios are indistinguishable, apart from the Brahmaputra water diversion flow scenario.

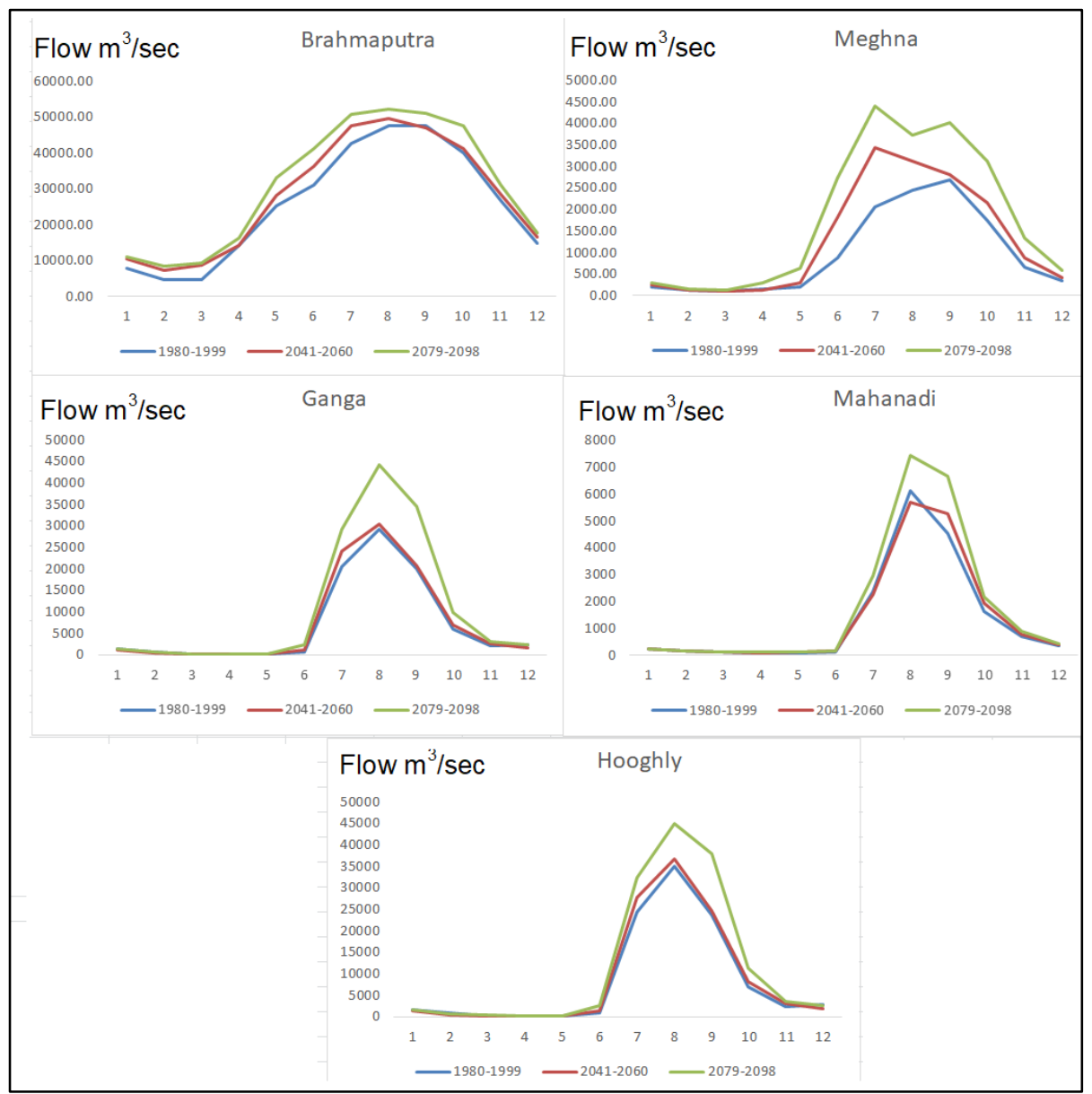

Figure 7 Impacts of Future Climate Change on Monthly Mean Flows in the last reaches of 5 Rivers for the downscaled HadGEM2-ES climate data.

Table 3 Simulated Current Flow Statistics for flood and low flow conditions and percentage changes into the future for the 5 River Systems for climate data downscaled from the GFDL-

\begin{tabular}{|l|l|l|l|l|l|l|}
\hline & \multicolumn{2}{|l|l|l|l|}{$\begin{array}{l}\text { 1990s Flow } \\
\mathrm{m}^{3} / \mathrm{sec}\end{array}$} & \multicolumn{2}{l|}{$\begin{array}{l}\text { 2050s Flow } \\
\text { \% change }\end{array}$} & \multicolumn{2}{l|}{$\begin{array}{l}\text { \% change } \\
\%\end{array}$} \\
\hline & Q5 & Q95 & Q5 & Q95 & Q5 & Q95 \\
\hline
\end{tabular}




\begin{tabular}{|l|r|r|r|r|r|r|}
\hline Brahmaputra & 50561.4 & 3529.6 & 6.8 & 55.6 & 13.7 & 55.6 \\
\hline Meghna & 3277.4 & 30.0 & 35.2 & 15.1 & 86.9 & 98.1 \\
\hline Ganga & 31116.3 & 127.2 & 5.9 & 3.5 & 56.7 & 37.0 \\
\hline Hooghly & 36600.2 & 148.4 & 9.6 & 3.5 & 29.5 & 37.0 \\
\hline Mahanadi & 6064.2 & 90.1 & 17.6 & -0.1 & 97.7 & 12.34 \\
\hline
\end{tabular}

417

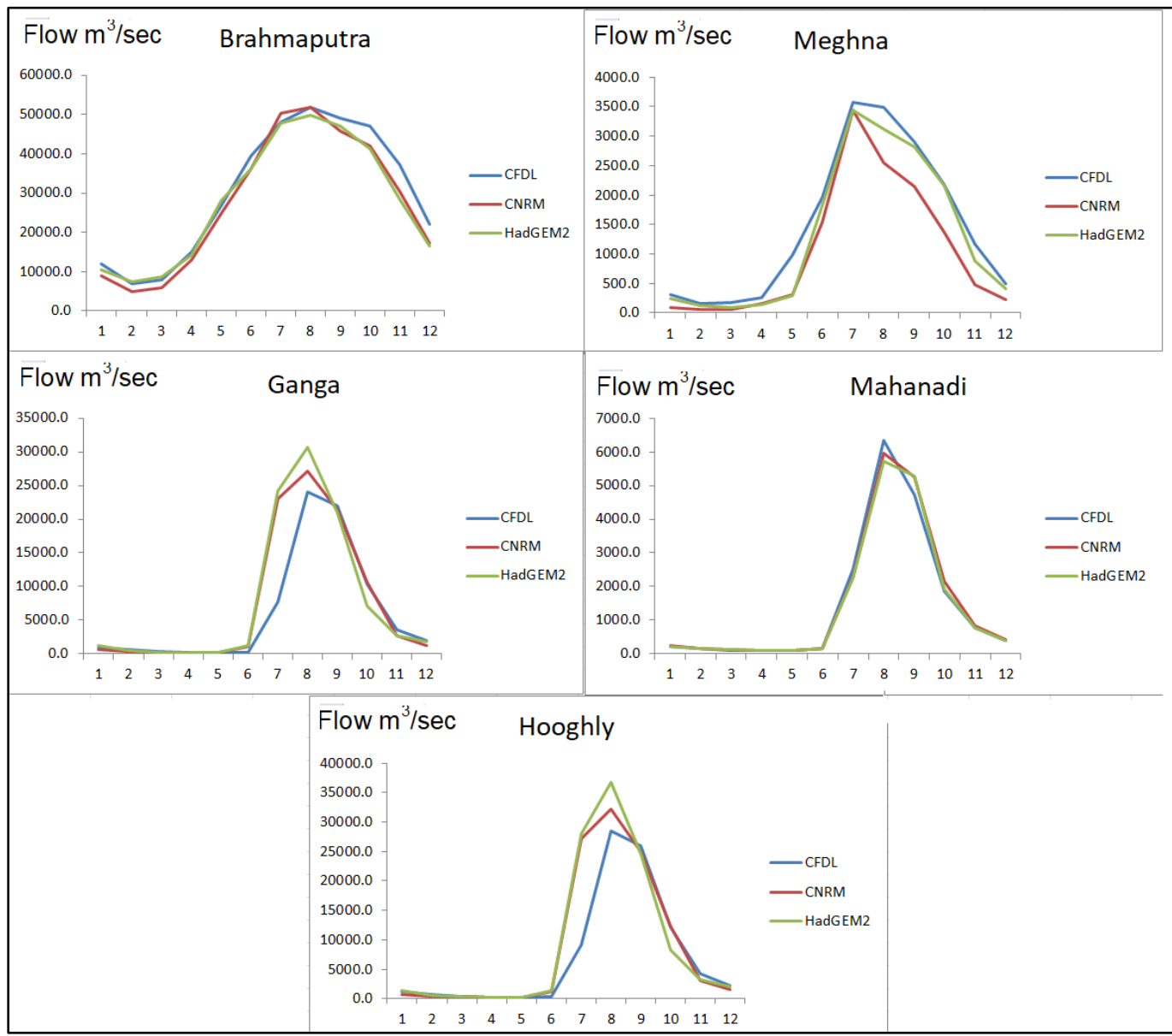




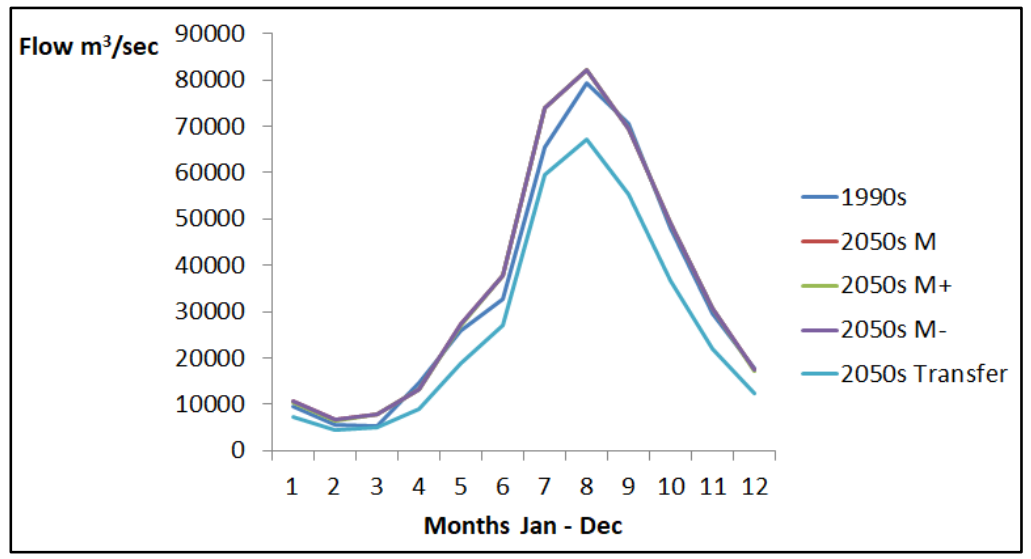

Figure 9 Impacts of Socio-Economic Change and also a Water Transfer Scheme in the 2050s

\section{EFFECTS OF CLIMATE AND SOCIO-ECONOMIC CHANGES ON WATER QUALITY}

In terms of water quality, the climate and socio-economic changes will impact Nitrate and Phosphorus in different ways. For example, Figure 10 shows the impacts of climate change on Nitrate and Phosphorus in the 2050s and 2090s for the Ganga River using climate data downscaled from the climate model combination GFDL-CM3. The higher monsoon flows in the 2050s and 2090s dilute the sources of $N$ and $P$ in the catchment and hence generate lower $\mathrm{N}$ and $\mathrm{P}$ in the high flow periods. However in the low flow periods $\mathrm{P}$ increases whereas $\mathrm{N}$ decreases. This is due to the different process affecting $\mathrm{N}$ and $\mathrm{P}$, where $\mathrm{N}$ undergoes extensive denitrification under low flows, due to the higher temperatures and the increased residence time of the river water. Whereas $P$ concentrations rise in the low flow periods as there is less dilution of effluent discharges and agricultural runoff.

Figure 11 illustrates the impacts on river nutrients of socio-economic changes combined with climate changes. The results suggest that socio-economics will have a fairly limited impact on water quality except in the case of the medium minus economy as it affects $P$ in the dry season. This is because there is the assumption that STWs will not be upgraded and with a decline in low flows plus there is less dilution of pollutants entering the River Systems. The resulting increasing $P$ will enhance eutrophication and lead to enhanced algal blooms, some of which are toxic, such as cyanobacteria (Bussi et al., 2016)
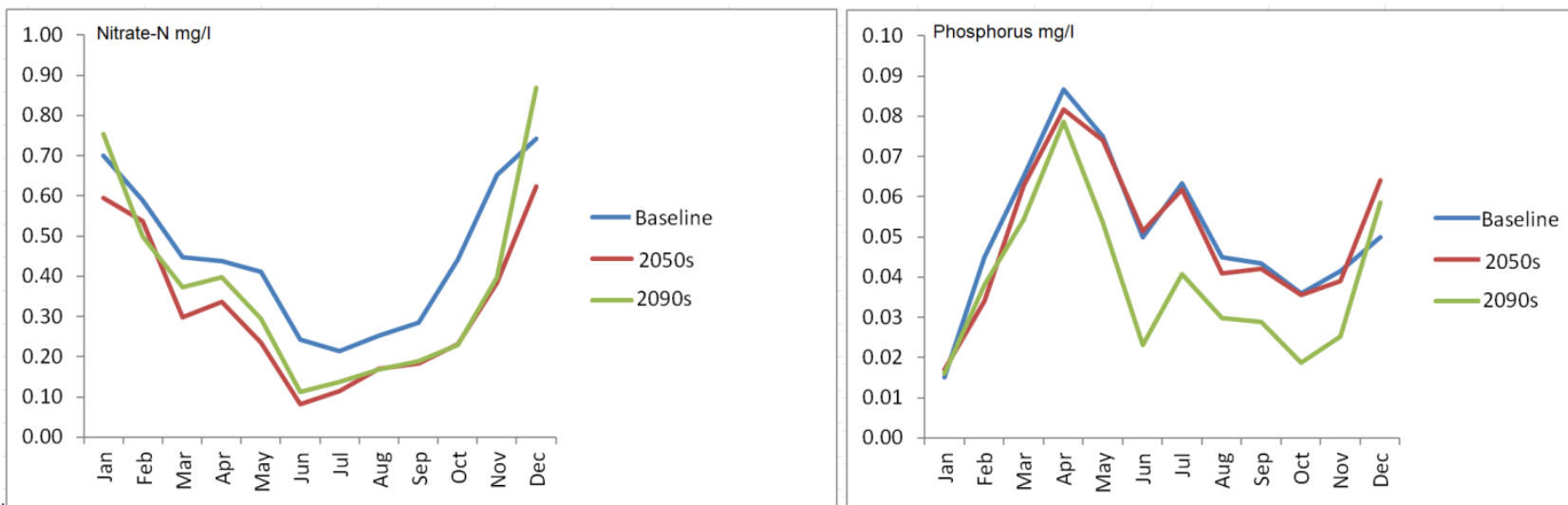

Figure 10 Impacts of Climate Change on Nitrate and Phosphorus in the 2050s and 2090s for the Ganga using climate data downscaled fromthe GFDL-CM3 GCM 

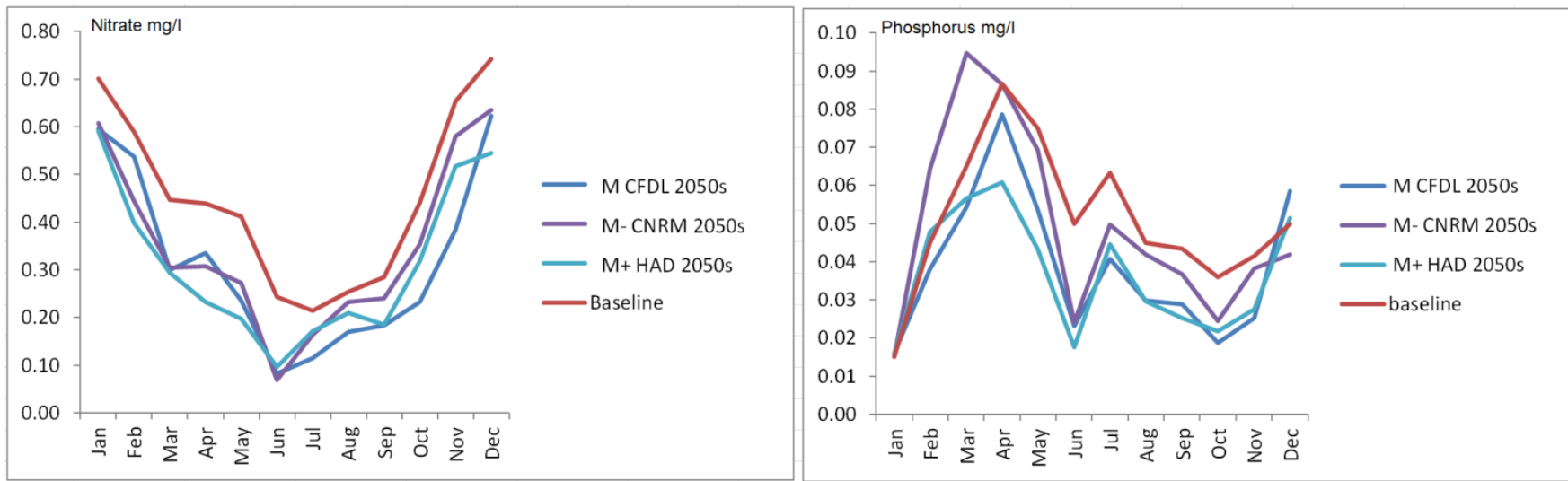

Figure 11 Impacts of Climate Change on Nitrate and Phosphorus concentrations in the 2050s for 3 climate scenarios (abbreviated to "GFDL", "CNRM" and "HAD") and 3 socioeconomic scenarios (abbreviated to "M", "M-" and "M+")

\section{DISCUSSION AND CONCLUSIONS}

The GBMHM Rivers are of crucial importance providing water for public supply, hydropower, irrigation water for agriculture, and are also of great cultural significance. In this study, INCA $\mathrm{N}$ and $\mathrm{P}$ have been applied the five rivers to assess the likely future impacts of climate change and socio-economic changes. It is recognised that there are a number of uncertainties within the model, input data and parameters. The lack of adequate flow and water quality data limits the ability to fully evaluate the model's performance. However, comparison with the data that is available demonstrates reasonable replication of the overall magnitude and pattern of flows and water quality.

The model results suggest that there is a significant increase in flows projected under a future climate change during the monsoon season. This is due to future increases in monsoon rainfall in the climate data downscaled from all three of GCMs that we have considered (Janes et al., 2018, this volume). Continuing emissions of greenhouse gases over the $21^{\text {st }}$ century are consistent with the RCP 8.5 scenario and result in increases in monsoon rainfall over the century in most of the current generation of GCMs. Hence, this result is likely to be robust to a different choice of GCMs for downscaling. The increased flows in the monsoon suggest there will be increased flooding into the future, which could have significant consequences for India and Bangladesh. Such changes in flow on a seasonal basis will also affect nutrients with $\mathrm{N}$ and $\mathrm{P}$ being diluted under the higher flows but phosphorus increasing in low flow conditions as dilution is reduced.

Changes to low flows are also likely to occur given projected increases in variability. Here, the model results suggest that drought duration may become more frequent, whilst extreme low flows may actually increase in extent. However, changes to low flows are likely to be more sensitive to uncertainties in climate projections and assumptions regarding landsurface runoff and river channel transport. In general, the socio-economic changes considered had minimal impact on flows. However, the magnitude of these changes is also uncertain and large scale water transfers will significantly alter flows (Whitehead et al., 2015) The socio-economic scenarios mostly affect the nutrient balance with increasing 
concentration of $\mathrm{N}$ and $\mathrm{P}$ under the medium minus scenario. However, these socioeconomic changes are offset by the changes in climate.

The development of models for such large and complex river systems provide an important planning tool for assisting in exploring future scenarios, engaging stakeholders in dialogue on water resources management, and identifying gaps in knowledge and data. Considering both flows and water quality for a range of climate and socio-economic scenarios can assist in a more holistic management approach.

\section{Acknowledgements}

The research has been supported by the DECCMA Project on 'DEltas, vulnerability and

Climate Change: Migration and Adaptation' which is part of Collaborative Adaptation Research Initiative in Africa and Asia (CARIAA), with financial support from the UK Government's Department for International Development (DfID) and the International Development Research Centre (IDRC), Canada.

\section{REFERENCES}

Arnell N W and Lloyd-Hughes B, 2013, The global-scale impacts of climate change on water resources and flooding under new climate and SSPs, Climatic Change (2014) 122:127-140 , DOI 10.1007/s10584-013-0948-4

Caesar, J., Janes, T., and Lindsay, A. 2015 Climate projections over Bangladesh and the upstream Ganges-Brahmaputra-Meghna system, Environ Sci Process Impacts. 2015 17(6):1047-56. doi: 10.1039/c4em00650j.

Collins, R., Whitehead, P.G. And Butterfield, D. (1999) Nitrogen Leaching from Catchments in the Middle Hills of Nepal; an application of the INCA model, Science of the Total Environment, 228, 259-274.

Futter, M.N., Butterfield, D., Cosby, B.J., Dillon, P.J., Wade, A.J., and Whitehead, P.G., 2007, Modeling the mechanisms that control in-stream dissolved organic carbon dynamics in upland and forested catchments: Water Resources Research, v. 43, p. W02424, doi:10.1029/2006WR004960.

Futter, M. N., Whitehead, P.G., S. Sarkar, H. Rodda and J. Crossman, 2015, Rainfall Runoff Modelling Of The Upper Ganga And Brahmaputra Basins Using Persist, Environ. Sci.: Processes Impacts, 2015,17, 1070-1081 DOI: 10.1039/C4EM00613E and R. A. Wood, 2000: The simulation of SST, sea ice extents and ocean heat transports in a version of the Hadley Centre coupled model without flux adjustments. Clim. Dyn.,16:147168

513 Hill, C., Nicholls, R J, Whitehead, P G, Dunn F, Haque, A., Appeaning-Addo, K, and Raju P 514 V, (2018), Delineating Climate Change Impacts on Biophysical Conditions in Populous

515 Deltas, Editorial, A special Issue of Science of the Total Environment, this volume

516 Hornberger, G. M. and Spear, R. C., 1980 Eutrophication in peel inlet: The problem-defining 517 behaviour and a mathematical model for the phosphorus scenario, In Water Research, 
Volume 14, Issue 1, 1980, Pages 29-42, ISSN 0043-1354, https://doi.org/10.1016/00431354(80)90039-1.

IPCC, 2014: Summary for Policymakers, In: Climate Change 2014, Mitigation of Climate Change. Contribution of Working Group III to the Fifth Assessment Report of the Intergovernmental Panel on Climate Change [Edenhofer, O., R. Pichs-Madruga, Y. Sokona, E. Farahani, S. Kadner, K. Seyboth, A. Adler, I. Baum, S. Brunner, P. Eickemeier, B. Kriemann, J. Savolainen, S. Schlömer, C. von Stechow, T. Zwickel and J.C. Minx (eds.)]. Cambridge University Press, Cambridge, United Kingdom and New York, NY, USA.

Janes, T., McGrath, F., Macadam, I., and Jones, R.G., 2018, High-resolution climate projections for South Asia to inform climate impacts and adaptation studies in the GangesBrahmaputra-Meghna and Mahanadi deltas. Science of the Total Environment, This Volume

Jin, L., Whitehead, P G, Sarkar, S., Sinha, R., Futter, M N, Butterfield, D, Caesar J., and Crossman J. , 2015, Assessing The Impacts Of Climate Change And Socio-Economic Changes On Flow And Phosphorus Flux In The Ganga River System, Environ. Sci.: Processes Impacts, 17, 1098-1110, DOI: 10.1039/C5EM00092K

Jin I., Whitehead P G, Rodda H, Macadam I, Sarkar S. 2018 RCP Climate Change Impacts of Flows and Water Quality in the Mahanadi River System, India, Science of the Total Environment, This Volume

Jones, R.G., Noguer, M., Hassell, D.C., Hudson, D., Wilson, S.S., Jenkins, G.J. and Mitchell, J.F.B. (2004) Generating high resolution climate change scenarios using PRECIS, Met Office Hadley Centre, Exeter, UK, 40pp April 2004

Kathpalia, G.N., and Kapoor, R., 2010, Management of Land and other Resources for Inclusive Growth: India 2050: Alternative Futures, Dehli, p. 32.

Kebede, A.S., Nicholls, R.J., Allan, A., Arto, I., Cazcarro, I., Fernandes, J.A., Hill, C.T., Hutton, C.W., Kay, S., Lawn, J., Lazar, A.N., Macadam, I., Palmer, M., Suckall, N., Tompkins, E.L., Vincent, K., and Whitehead, P.G., 2018, Integrated Scenario Framework to Explore Migration and Adaptation in Deltas: The DECCMA Approach: Science of the Total Environment, This Volume.

Nash, J. E. and Sutcliffe, J. V. 1970. River flow forecasting through conceptual models part I-A discussion of principles. Journal of Hydrology 10 (3): 282-290. doi:10.1016/00221694(70)90255-6

Nicholls, R.J., C.W. Hutton, A.N. Lázár, A. Allan, W.N. Adger, H. Adams, J. Wolf, M. Rahman, and M. Salehin. 2016. Integrated assessment of social and environmental sustainability dynamics in the Ganga-Brahmaputra-Meghna delta, Bangladesh. Estuarine, Coastal and Shelf Science 183, 370-381. http://dx.doi.org/10.1016/j.ecss.2016.08.017

Nicholls, R J, Wolf, J, Whitehead P G, Rahman M , Salehin, M, Hutton C, 2015 A Synthesis of Environmental Change impacts on the ESPA DELTA region (this volume|)

Nicholls, R. J., Whitehead, P., Wolf, J., Rahman, M., \& Salehin, M. (2015). The GangaBrahmaputra-Meghna delta system: biophysical models to support analysis of ecosystem 
services and poverty alleviation. Environmental Science: Processes \& Impacts, 17(6), 10161017. DOI: $10.1039 / C 5 E M 90022 K$

Pathak D., Whitehead P G, Futter M N and Sinha R, 2018 Water Quality Assessment And Catchment-Scale Nutrient Flux Modeling In The Ramganga River Basin In North India: An Application Of The INCA Model Science of the Total Environment (this Volume)

Rankinen, K., Karvonen, T., Butterfield, D., 2006. An application of the GLUE methodology for estimating the parameters of the INCA N model. Science of the total environment, 365(1): 123-139.

Roy, N.G. and Sinha, R. (2014). Effective discharge for suspended sediment transport of the Ganges river and its geomorphic implications. Geomorphology, 227, 18-30.

Sadoff, C 2013 Ten fundamental questions for water resources development in the Ganga: myths and realities, Water policy 15 (2013): 147-164.

Shi, Y., Gao, X., Zhang, D., and Giorgi, F.: Climate change over the Yarlung ZangboBrahmaputra River Basin in the 21st century as simulated by a high resolution regional climate model, Quaternary international, 244, 159-168, 2011.

Sinha, R., Jain, V., Babu, G.P., Ghosh, S., 2005. Geomorphic characterization and diversity of the fluvial systems of the Gangetic Plains. Geomorphology, 70(3): 207-225.

Spear RC and Hornberger GM, 1980 Eutrophication in the Peel Inlet II. Identification of critical uncertainties via generalised sensitivity analysis. Water Research 1980;14:43 - 49.

Wade, A .J., Durand, P., Beaujouan, V., Wessel, W. W., Raat, K. J., Whitehead, P. G., Butterfield, D., Rankinen, K. And Lepisto, A., 2002a Towards a generic nitrogen model of European ecosystems: INCA, new model structure and equations. Hydrol. Earth Syst. Sci., $6,559-582$.

Wade, A.J., Whitehead, P.G., Butterfield, D., 2002b. The Integrated Catchments model of Phosphorus dynamics (INCA P), a new approach for multiple source assessment in heterogeneous river systems: model structure and equations. Hydrology and Earth System Sciences, 6(3): 583-606.

Wade, A., Whitehead, P., Hornberger, G., Jarvie, H., Flynn, N., 2002c. On modelling the impacts of phosphorus stripping at sewage works on in-stream phosphorus and macrophyte/epiphyte dynamics: a case study for the River Kennet. Science of the total environment, 282: 395-415.

Whitehead, P. G. Sarkar, S. and Jin, L. and Futter, M. N. and Caesar, J. and Barbour, E. and Butterfield, D. and Sinha, R. and Nicholls, R. and Hutton, C. and Leckie, H. D., 2015, Dynamic Modelling Of The Ganga River System: Impacts Of Future Climate And SocioEconomic Change On Flows And Nitrogen Fluxes In India And Bangladesh, Environ. Sci.: Processes Impacts, 17,6 1082-1097, doi 10.1039/C4EM00616J

Whitehead, P.G., E. Barbour, M. N. Futter, S. Sarkar, H. Rodda, J. Caesar, D. Butterfield, L. Jin, R. Sinha, R. Nicholls and M. Salehin , 2015, Impacts Of Climate Change And SocioEconomic Scenarios On Flow And Water Quality Of The Ganges, Brahmaputra And Meghna 
596 (GBM) River Systems: Low Flow And Flood Statistics, Environ. Sci.: Processes Impacts, 597 2015,17, 1057-1069, DOI: 10.1039/C4EM00619D

598 Whitehead P.G., Wilson E.J., Butterfield D. 1998a A semi-distributed Integrated Nitrogen 599 model for multiple source assessment in Catchments (INCA): Part I - model structure and 600 process equations. Science of the Total Environment, 210/211, 547-558.

601 Whitehead P.G., Wilson E.J., Butterfield D., Seed K. 1998b A semi-distributed Integrated 602 flow and Nitrogen model for multiple source assessment in Catchments (INCA) : Part II 603 application to large river basins in south Wales and eastern England. Science of the Total 604 Environment, 210/211, 559-583.

605 Whitehead P G, Water Quality Modelling, (2016) Wiley Statistics John Wiley \& Sons, Ltd. 606 DOI:10.1002/9781118445112.stat07793.pub2 